\title{
The effectiveness of local authority social services' occupational therapy for older people in Great Britain: a critical literature review
}

\author{
Gail Boniface, ${ }^{1}$ Margot Mason, ${ }^{2}$ Jacqueline Macintyre, ${ }^{3}$ Christine Synan, ${ }^{4}$ and Jill Riley ${ }^{5}$
}
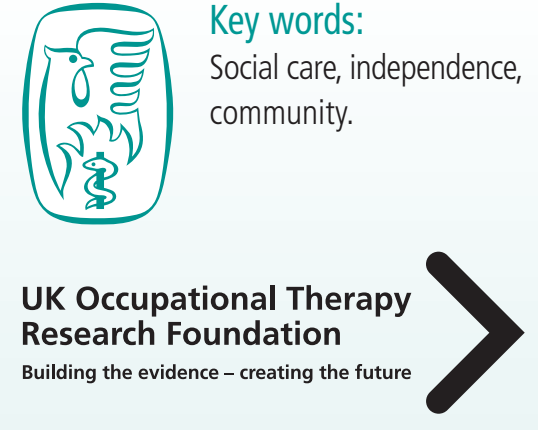

${ }^{1}$ Senior Lecturer, Cardiff University, Occupational Therapy, Cardiff.

2Professional Team Lead for Occupational Therapy, Gloucestershire Care Services NHS Trust, Gloucester.

${ }^{3}$ Team Leader — Physical Disability and Sensory Impairment, Inverclyde Council, Centre for Independent Living, Greenock.

${ }^{4}$ Operational Manager — Maintaining and Regaining Independence, Health and Social Care, Cardiff County Council, Cardiff. ${ }^{5}$ Lecturer, Cardiff University, Occupational Therapy, School of Healthcare Studies, Ty Dewi Sant Heath Park, Cardiff.

Corresponding author: Dr Gail Boniface, Senior Lecturer, Cardigan House Heath Park, Cardiff CF14 4XN.

Email: Boniface@cardiff.ac.uk

Reference: Boniface GE, Mason M, Macintyre J, Synan C, Riley J (2013) The effectiveness of local authority social services' occupational therapy for older people in Great Britain: a critical literature review. British Journal of Occupational Therapy, 76(12), 538-547.

DOI: $10.4276 / 030802213 \times 13861576675240$

(C) The College of Occupational Therapists Ltd. Submitted: 28 November 2012.

Accepted: 12 August 2013.
Introduction: Older people are the main users of adult social care services in Great Britain. Evidence suggests that occupational therapists employed by local authorities are providing interventions that promote and maintain older people's independence, and decrease dependency on other services. However, such evidence is disparate in nature and lacks synthesis.

Method: This literature review systematically selected, critically appraised, and thematically synthesized the post 2000 published and unpublished evidence on the effectiveness and cost effectiveness of occupational therapy interventions for older people in social care services.

Findings: Identified themes established: the localized nature of social care services for older people; organizational and policy impacts on services, and factors influencing effectiveness and cost effectiveness. Although occupational therapists are increasingly involved in rehabilitation and reablement, there is a continuing focus on equipment and adaptations provision. A high level of service user satisfaction was identified, once timely occupational therapy services were received.

Conclusion: Overall, occupational therapy in social care is perceived as effective in improving quality of life for older people and their carers, and cost effective in making savings for other social and healthcare services. However, the complex nature of social care services makes it difficult to disaggregate the effectiveness of occupational therapy from other services.

\section{Introduction}

Social care services for older people are a part of local authority adult social care services in England, social work services in Scotland, and social services in Wales. In Northern Ireland, health and social care is integrated into one structure (College of Occupational Therapists [COT] 2010). Occupational therapists are employed in all of these services. However, in view of Northern Ireland's organizational differences, which inevitably impact on service delivery, this critical review of the literature relating to occupational therapy for older people in local authority social services focused on England, Scotland, and Wales (Great Britain).

Older people are the main users of health and social services (Department of Health [DH] 2001) and the number of older people in the United Kingdom (UK) as a whole is expected to rise, with the fastest projected increase in those over the age of 85 years (Office for National Statistics 2012). This growth in a potentially frail population will place further pressures on social care services, including occupational therapy, at a time of increasingly scarce resources. Such pressures place an onus on the profession to demonstrate the effectiveness of its services for older people in social care settings. 
Across Great Britain, National Service Frameworks and strategies for older people emphasize the need for services, such as occupational therapy, that help people to manage and maintain independence in their own homes and communities for as long as possible, and prevent the need for hospital admission or long-term care (DH 2001, Welsh Assembly Government [WAG] 2008, Scottish Executive 2007a). Government policies relating specifically to local authority social care services in England, Scotland and Wales (DH 2008, Scottish Executive 2006, WAG 2007) state that this is achievable through a preventative and enabling approach to social service provision that reduces the need for complex and costly packages of care. A review of the literature on occupational therapy in local authority social services prior to 2000 identified the importance of occupational therapy interventions in maintaining older people's independence (Mountain 2000). Since then, occupational therapists have continued to play a key role in promoting individuals' self-reliance and resourcefulness (COT 2008).

Occupational therapists in adult social care services make up approximately $2 \%$ of the social care workforce in all three countries (Information Centre for Health and Social Care 2011, Scottish Government 2011, Welsh Government 2011) Despite their small numbers, occupational therapists are reported as handling over 35\% of adult social care services' referrals and their skills have been identified as key to the delivery of Government policies in England, Scotland, and Wales. Since Mountain's (2000) review of the literature, no systematic reviews of evidence relating to occupational therapy for older people have concentrated specifically on social care services within Great Britain.

\section{Policy context}

Each country has, since devolution in Scotland and Wales in 1997, developed its own social care policy drivers and directives, which impact on the delivery of occupational therapy services. At the time of the review these were: Changing Lives in Scotland (Scottish Executive 2006), Fulfilled Lives, Supportive Communities in Wales (WAG 2007) and Putting People First in England (DH 2008). Scotland also introduced a rehabilitation framework (Scottish Executive 2007b) and all three countries have developed strategies for older people (DH 2001, Scottish Executive 2007a, WAG 2008) and frameworks for action. Whilst there are discrete differences, and services are broadly addressed, all emphasize a person-centred approach, and promotion of self-reliance and resourcefulness for service users, principles which are central to occupational therapy in social care services. Taking into account the changes in policy and organizational drivers that have had an impact on social care services since 2000 , this review aimed to critically appraise and synthesize the post 2000 evidence on the effectiveness of occupational therapy interventions for older people in preventing the need for complex packages of care in social care services in Great Britain.

\section{Method}

A systematic approach was employed to identify, select, critically appraise, and synthesize the available published and unpublished evidence to address the research questions, which were revised during the review period (Table 1).

\section{Table 1. Research questions}

\section{Final research questions}

1. What are the legislative, policy, guidance, and local organizational factors that influence the delivery of occupational therapy interventions in England, Scotland, and Wales?

2. What interventions do local authority social services occupational therapists use with older people? (Local authority social services occupational therapists, and interventions are defined as where the service or therapist works to the social care and housing legislation).

3. Do interventions differ between England, Scotland, and Wales?

4. How effective are social services' occupational therapy interventions for maximizing older people's ability to remain living in the community?

5. What are the outcomes of social services' occupational therapy interventions for older people and their informal carers?

6. Are social services' occupational therapy interventions cost effective in terms of reducing the extent of and/or the need for packages of care?

This article concentrates on the findings that addressed the revised questions 4, 5, and 6; specifically the contextual factors that impact on the perceived effectiveness and cost effectiveness of occupational therapy in social care services, which was the main focus of the review. Questions 1-3 are addressed in the final research report (Riley et al 2012).

\section{Inclusion criteria}

Literature included published peer-reviewed articles; literature accessible via electronic databases and library holdings; published reports and evaluations; current research activity; and grey literature (that is, unpublished dissertations and local authority service evaluations) from January 2000 to February 2012, relating to:

- Older people living in the community.

- Local authority based occupational therapy services.

- Local authority occupational therapists' interventions.

\section{Exclusions}

Literature published before 2000 and/or relating to non local authority occupational therapy provision, or from outside Great Britain was excluded.

\section{Theoretical approach}

Traditional systematic reviews of the effectiveness of health interventions usually recognize a hierarchy of evidence. Such reviews aim to be 'context-free' with randomized control trials (RCTs) and are considered the 'gold standard' (National Institute for Health and Clinical Excellence [NICE] 2009, p32). However, in social care, as in public health, communitybased interventions tend to be complex and dependent on context (Rychetnik et al 2002). To account for this, effectiveness 
reviews can include qualitative as well as quantitative and experimental studies (NICE 2009). Therefore, the mix of research traditions underpinning studies included in this review meant that different appraisal methods and a flexible approach were required. In line with Social Care Institute for Excellence (SCIE) (2010) guidance on conducting systematic reviews in social care, this review aimed to achieve comprehensive coverage from a wide range of sources. Included studies were subject to a rigorous quality appraisal, but were not excluded on grounds of methodological quality alone. In view of this approach, the resulting thematic synthesis was both aggregative and interpretive in nature (Thomas and Harden 2008).

\section{Review process}

The collaborative team who carried out the review included two researchers (both occupational therapists/academics with a social services background); three practice collaborators (one from each country working in social care settings), and a carer of an older adult, with experience of social services. All team members contributed to the research design and reviewed the methods and processes as the review progressed. They also commented on report drafts. In addition, the practice collaborators also appraised selected papers.

The methods incorporated in the review process are outlined sequentially, below. It should be noted, however, that stages overlapped, and search strategies, research questions, and inclusion criteria were revisited at certain points during the process. The historical, social, political, and organizational contexts of included studies were taken into account during appraisal, synthesis, and reporting.

\section{Literature search and retrieval}

The search strategy was shaped initially by the review questions and informed by the team's prior knowledge of the field and an initial search. The strategy aimed to be comprehensive, while taking into account the need for maximum variability (Thomas and Harden 2008), and was developed and refined as the project proceeded.

\section{Search strategy}

Published literature was accessed through electronic databases (Cinahl, AMED, Medline, ASSIA, EMBASE, OTseeker, OTDbase, HMIC, Cochrane and Campbell collaborations) and library holdings. Grey literature was accessed through the COT and university libraries and the System for Information on Grey Literature (SIGLE).

Websites (for example, SCIE, COT, social care policy units, and local authorities) were searched for policy documents and reports, and for current and ongoing research. In addition, occupational therapy networks in all three countries were approached for assistance with identifying relevant local authority evaluations, service user satisfaction, and audit reports. Although no ethical issues were identified, electronic consent was obtained for the use of reviewed unpublished reports where appropriate. Search terms (see Table 2) were used in combination.
Table 2. Search terms

\begin{tabular}{ll}
\hline $\begin{array}{l}\text { adaptations } \\
\text { benefits }\end{array}$ & informal carer \\
$\begin{array}{l}\text { care management } \\
\text { care packages }\end{array}$ & maximising \\
community & moving and handling \\
dependency & occupational therapy \\
dependent & older people/older adults/elderly \\
effectiveness & outcomes \\
evaluation & reablement/enablement \\
home care & rehabilitation \\
housing & role of occupational therapy in the community \\
independence & social services/adult social care services/adult \\
independent & social services \\
intervention & UK/Great Britain \\
\hline
\end{tabular}

\section{Refining the appraisal templates}

The mix of methods across relevant literature meant that different methods of appraisal were also required. Appraisal templates have been developed for use with different types of study by the Critical Appraisal Skills Programme (CASP) (University of Oxford 2005). Others, aimed more explicitly at social care studies, are available from SCIE and were developed by Long and Godfrey (2004) to take account of organizational and local contexts. These different templates were tested by the research team for their efficacy and appropriateness on published studies from the following categories: a randomized control trial (RCT), and a qualitative and quantitative (non-experimental) design. Appropriate templates (related to research design) were also tested on an unpublished research report and a service evaluation. An adapted template was then designed and refined for use with a wide range of literature.

\section{Data evaluation process}

Data evaluation took place in two stages:

\section{Stage 1: Screening and assessing for relevance}

Literature was screened and assessed for relevance, initially according to the inclusion criteria and research questions. To maximize inclusion, no restrictions were placed on study design. Methodological quality was assessed during stage 2 (appraisal). In total, 72 articles and reports (both published and unpublished) were included. See Fig. 1 for full search results.

\section{Stage 2: Critical appraisal}

Fig. 2 presents an overview of the appraised literature and shows the numbers and types of study reviewed. All studies were appraised by two reviewers independently, using the adapted template; reviewers whose reports or articles were included did not appraise their own work. Sensitivity analysis was used to assess the impact of quality on findings (Thomas and Harden 2008). 
Fig. 1. Search results.

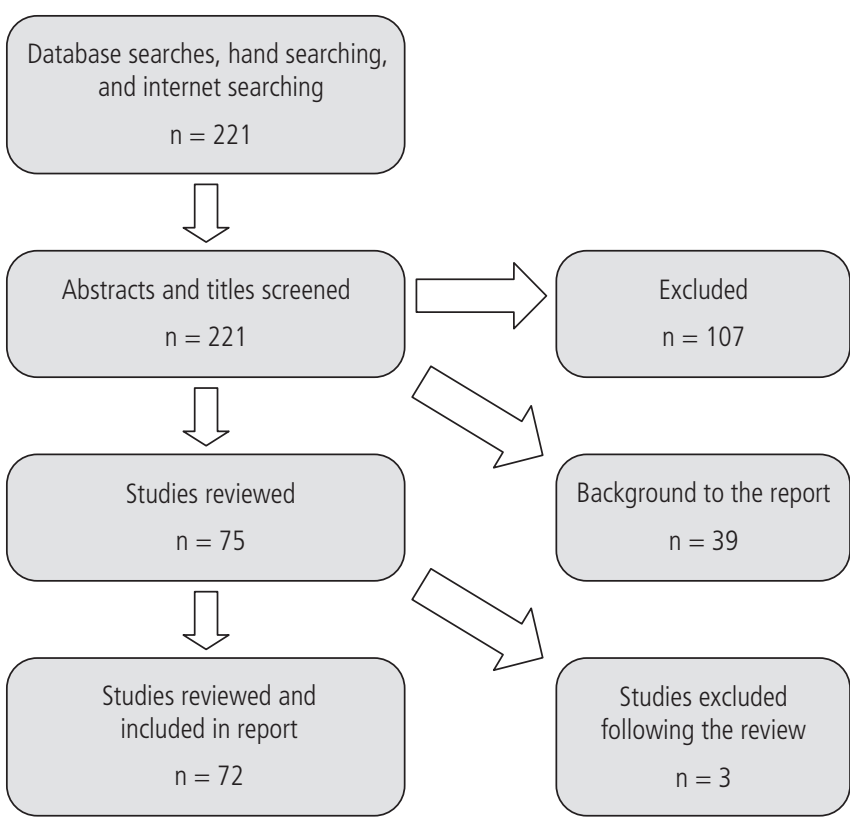

Note: Of the three excluded studies, two did not delineate occupational therapy from other social services, and one was speculative, using notional case studies.

\section{Quality}

The following quality issues were addressed during the appraisal process: rigour in the application of research methods, validity, and approach; credibility and reliability of findings; relevance of findings to review aim and objectives; and description of the setting and context. The team found that most of the research-based literature relating specifically to occupational therapy in social care services for older people reported on small-scale local studies, which were both qualitative and quantitative in nature. The findings from these studies were considered to be transferable to other similar settings and contexts. Of the mixed-methods studies appraised, the larger scale studies tended to address more general issues such as reablement, shared assessments processes, eligibility criteria, or types of services. These generalizable studies were rigorously conducted, and informed the review on issues impacting on the nature and delivery of social services' occupational therapy interventions. The few pragmatic RCTs compared interventions or services within and between authorities. The unpublished evaluation and audit reports received from individual authorities were variable in quality; some were presented as full reports and others as raw data on, for example, service user satisfaction.

\section{Data extraction and synthesis}

Following Thomas and Harden's (2008) methods for developing a thematic synthesis, study findings were identified independently by two reviewers, and a consensus was reached. Agreed findings were entered into an overview document and then coded for meaning and content. Codes from each study were added to a coding framework, and new ones were developed as necessary. During this stage the reviewers checked for consistency in interpretation, and descriptive themes were identified.

\section{Generating analytical themes}

The first stage of this process resulted in an aggregative synthesis that summarized and described the data under key concepts (Thomas and Harden 2008) but remained close to the original study findings. The second stage moved beyond this, through further interpretation, using the descriptive themes to address the review questions and develop more analytical themes. Each reviewer did this independently and then together. The process was repeated until the themes were sufficiently refined (Thomas and Harden 2008).

Overall, the main weaknesses, which had an impact on the findings from this review, can be summarized as a lack of detail on the context or study location; limited description

\section{Fig. 2. Overview of literature appraised.}

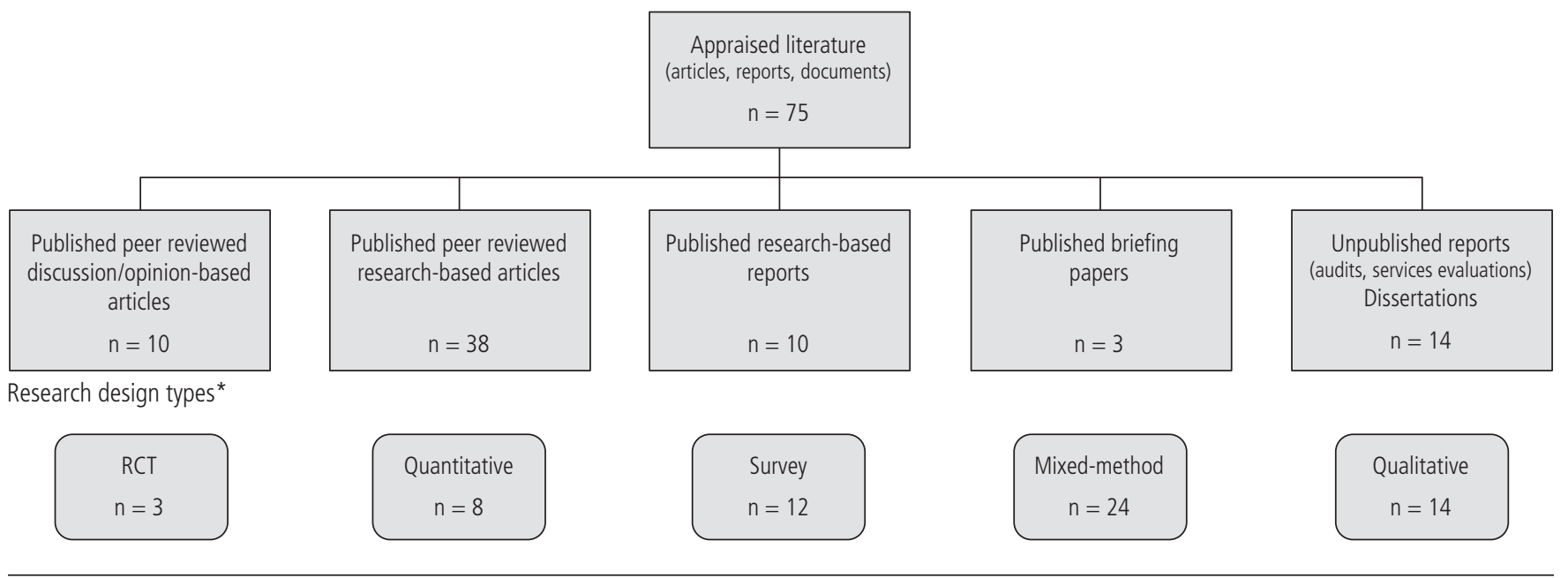

*These number 61 in total, since 14 were removed as follows: 10 papers were discussion based and 3 were briefing papers; one report was discussion based. 
of participants, or explanation of the service, team, or intervention; a medical, rather than social model perspective, and a lack of reflexivity, with the researcher appearing to be part of the setting being researched. Such quality issues clearly have an impact on claims made for the effectiveness or cost effectiveness of occupational therapy services within individual studies. To take account of this, and of the contextual nature of included studies, the term perceived effectiveness has been used in the report of the review findings below. A summary of the quality appraisal of the 75 reviewed papers is available as an appendix to the full research report (Riley et al 2012).

\section{Review findings}

A full list of the themes established in the review is provided in Table 3. The following sections concentrate on the nature of occupational therapy social care service provision and interventions for older people; influencing factors; perceived effectiveness, and cost effectiveness.

\section{Table 3. Review themes}

The nature of occupational therapy social care service provision for older people in Great Britain

Influences on occupational therapy service provision

Occupational therapy professional issues

Access to services

Occupational therapy intervention

Effectiveness

Collaboration/relationships with other services/multidisciplinary working

Service user issues

Issues for carers

Reshaping occupational therapy services

Time related to occupational therapy service provision for older people

Communication issues pertinent to occupational therapy service provision for older people

\section{The nature of occupational therapy social care services for older people}

The review identified that the majority of adult social care service users in England, Scotland, and Wales were over 60 years of age (Inverclyde Council 2010, Reid-Howie Associates 2000, Tucker et al 2011) and women (Chamberlain et al 2001, Heywood 2001, Miller and Foulkes 2011). Consequently, both the nature of services for adults and the influencing factors were found to be relevant to older people.

Occupational therapy social care services across Great Britain are historically driven by Government legislation. Adherence to the Chronically Sick and Disabled Persons Act 1970 (Great Britain. Parliament 1970 [1972 in Scotland]) especially, has led to occupational therapists in social services being heavily involved in adaptation and equipment provision. The review findings confirmed that during the twelve year timeframe, occupational therapy remained centred around adaptations and equipment provision (Stubbs et al 2004, Forsyth and Hamilton 2008). Services also focused mainly on self-care (Armstrong 2001, Brittle et al 2007, Heywood 2004, Inverclyde Council 2010, Miller and Foulkes 2011, Sainty et al 2009, Tucker et al 2011). During the review timeframe, however, policy initiatives began focusing on enabling older adults and the creation of reablement services (Scottish Executive 2007a, Social Services Improvement Agency Wales 2011). Although not all reablement teams include occupational therapists, the fact that access to an occupational therapist is crucial to reablement provision (Rabiee and Glendinning 2011) was identified.

\section{Influences on occupational therapy service provision}

There are numerous influences on the provision of occupational therapy services in social care. These include workforce issues such as recruitment and retention (Wilson 2010); organizational factors such as workforce planning, career structures, eligibility criteria, and priority systems. The latter operated across local authorities in all three countries and had an impact on working practices and access to services. Despite organizational attempts to create standardization, for example through the introduction of Fair Access to Care Services (FACS) in England (Lett et al 2006, Sackley et al 2009), services remained variable and localized (Lett et al 2006). In addition, the high referral rates, which contributed to lengthy waiting lists for occupational therapy services in many authorities impacted on staff morale (Hunt and Cook 2001, Wilson 2010), which, in turn, affected professional autonomy and, consequently, the perceived effectiveness of occupational therapy intervention and service delivery.

\section{Perceived effectiveness}

The sub-sections below include some general points from the literature on the perceived effectiveness of occupational therapy interventions and services for services users, carers, professionals, and the organization; how effectiveness might be achieved and where it is lacking. Outcomes are also addressed, including how these are measured and the inherent problems in doing this in social services settings. Later sections consider service user satisfaction as a means of establishing effectiveness followed by a review of cost effectiveness and evaluation.

\section{General aspects of effectiveness}

Occupational therapy is perceived to be effective in improving independence and quality of life for older people living in their own homes (Armstrong 2001). Claims for the effectiveness of equipment (or assistive technology) and adaptations, especially, were made in several articles. Mountain (2004) found that assistive technology was important in preventing accidents, reducing the fear of falling, maintaining dignity, and independence for service users. Equipment provision was described as 'pivotal' in enabling 
service users to engage with everyday activities (Forsyth and Hamilton 2008, p69), and good housing adaptations promoted functional independence and improved quality of life for service users and carers (Heywood 2001, Heywood and Turner 2007, Mountain 2004).

Where reablement services were in place, these too were perceived to be effective in maintaining people in their own homes and improving independence. Littlechild et al (2010) found that an independence at home service both promoted independence and reduced re-referral. An evaluation of a community rehabilitation service in Scotland (Inverclyde Council 2010) indicated that this type of service could improve independence and reduce care packages. In general, maintaining people at home through occupational therapy interventions reduces the need for hospital admissions. Several authors also suggested strategies that contribute to effectiveness.

\section{Perceived effectiveness strategies}

The perceived effectiveness of occupational therapy interventions and services depends not only on the nature of the interventions themselves but also the professionals and organizational structures involved. Littlechild et al (2010) identified three important features for promoting or maintaining service user independence: speed of response, assisting family carers, and adequate time. In a study of older people's participation in the disabled facilities grant process, Awang (2002) found that personal attention from professionals was an important feature. The perceived effectiveness of intervention in a reablement service also depended on the staff working with service users in order to enable independence (Weetman 2002).

On an organizational level, streamlining professional working practices was also seen as improving effectiveness. For example, the use of technology, fast-tracking telephone or self-assessments, streamlining working arrangements, and using support staff appropriately. The findings from an audit of an occupational therapy intake team in Wales, conducted in 2009 (Miller and Foulkes 2011), offers a good example of this. Their findings indicated that assessing people with straightforward needs and providing the appropriate equipment and adaptations in a 13-week target time was an effective way of managing referrals and preventing re-referral. The service also used occupational therapy assistants to assess and intervene in less complex cases (Miller and Foulkes 2011), to good effect.

It was also suggested that occupational therapy posts in other local authority departments, such as housing, offered opportunities for more coherent and timely service delivery at local level (Grisbrooke and Scott 2009). In order to prove the effectiveness of occupational therapy services, however, managers need to be skilled in conducting and designing service reviews (Skelton 2006).

\section{Outcomes}

Measuring outcomes has become an accepted way of establishing the effectiveness of interventions, especially in healthcare settings. Heaton and Bamford (2001) argued that because outcome measures are commonly developed and validated for hospital settings where there is a focus on improvement following intervention, their applicability to the community is questionable. In social care the focus is often on maintenance rather than improvement. Therefore, equipment and adaptations may be provided to maintain performance, especially for older people. Glendinning et al (2008) found that maintenance outcomes were important where the focus was on preventing deterioration, whereas change outcomes were important as a means of enabling functional improvement. Social care reablement services, for example, focus on outcomes that improve performance in daily activities, and service users' perceived quality of life (Francis et al 2011). It was acknowledged, however, that attributing change to occupational therapy alone is difficult, especially where other agencies are involved (Heaton and Bamford 2001).

There was a general view that social services' occupational therapy outcomes should be measured, and that standardized methods have been used in some areas. The Care Services Efficiency Delivery Programme (CSED) (2007) reported use of the Community Dependency Index (CDI), the Barthel Index, the Morriston Occupational Therapy Outcome Measure (MOTOM), and the Canadian Occupational Performance Measure (COPM). The CDI, for example, was used in the CAMELOT RCT, conducted to establish whether, on a range of clinical outcomes and, primarily, dependency in self-care, there was any significant difference between occupational therapy-led and social work-led assessments for frail older people and their carers (Flood et al 2005, Stewart et al 2005). No significant differences were found; in terms of outcomes, the conclusion was that both social work services and occupational therapy are successful in making care assessments that enable older people to remain at home (Flood et al 2005). However, the timescale for measuring the outcome of occupational therapy ( 8 months) was considered too short to take into account the effectiveness of interventions such as adaptations. Indeed, timing - particularly where adaptations are concerned - was a major issue (Heywood and Awang 2011). Outcomes should not just be measured straight after provision but also in the medium and longer term (Heaton and Bamford 2001).

It would seem that standardized measures have their place in evaluating the effectiveness of specific interventions where it is possible to establish a baseline score and a measure post intervention. However, taking into account the inherent variables in social care settings, there is also an argument for developing client-centred localized outcome measures (Armstrong 2001) that focus on the outcomes people want, rather than on what services provide (Glendinning et al 2008). Establishing service user views of how effective services were for them (in the timeframe for this review) was commonly achieved through the use of service user satisfaction questionnaires. 


\section{Service user satisfaction}

During this review, a range of published articles was found reporting service user and carers' views of services; several unpublished reports were sent to the research team from authorities in all three countries, or came from the grey literature. The findings from this body of literature as a whole indicate a high level of satisfaction among service users and carers with occupational therapy interventions and services, once received. In a review of English local authorities, Skelton (2006) found that this was the case despite waiting lists; similarly, reports from Scotland indicated that once in the system, service users were mostly satisfied with the occupational therapy service (Reid-Howie Associates 2000). Other reports also indicated that the general trend in satisfaction continued across England, Scotland, and Wales (for example, Chamberlain et al 2001, Equipu 2010, Miller and Foulkes 2011, Sainty et al 2009).

Where housing adaptations were concerned, good adaptations gave positive long-term outcomes for recipients, carers, and families, and could prevent admission to care (Heywood 2001, 2004). Satisfaction levels were also high for rehabilitation and reablement services (Francis et al 2011, Inverclyde Council 2010, Kent et al 2000, Jones et al 2009, McLeod and Mair 2009, SSIA 2011, Walden 2011a, 2011b). However, Littlechild et al (2010) found in their evaluation of an independence at home service that service users' perceived satisfaction in performance was not necessarily matched by improved performance.

Despite the generally high levels of satisfaction with occupational therapy services, a few authors also addressed the reasons for dissatisfaction, which are important to note if improvements are to be made. Concerns included charging policies; waiting lists for provision; difficulties in making contact; lack of follow up; inconsistencies in service provision; inadequate communication; poor installation; repairs and servicing; and the impact adaptations had on others in the household (Heywood 2001, Mountain 2004, Reid-Howie Associates 2000). In addition to satisfaction for service users and carers, the cost effectiveness of occupational therapy services is also a concern for the organization.

\section{Cost effectiveness}

The potential for cost effectiveness was generally reported in terms of the savings that occupational therapy could make for other parts of the service. For example, by maintaining older people in their own homes, reducing care packages, and preventing dependency on other services (Heywood 2001, Heywood and Turner 2007, Lansley et al 2004). Housing adaptations were identified as benefiting not just the individual and their family but also health and social care providers because of reduced demand for other services if adaptations were perceived to be effective.

The payback period from investing in adaptations and equipment for older people was considered short and worthwhile, with costs being recouped within the individual's life expectancy time (Lansley et al 2004). Equipment costs, particularly, were considered to be low compared with the benefits (Sainty et al 2009). Of the few studies that offered concrete evidence of cost effectiveness of specific services, a cost-benefit analysis conducted by an equipment service in Scotland (Equipu 2010) demonstrated significant potential savings in care costs. Others suggested, however, that the cost of older peoples' adaptations would not necessarily offset home care costs because a proportion of older people receive no home care, or remain frail and still need care despite adaptations (Heywood and Turner 2007). Indeed in an economic evaluation, conducted alongside the CAMELOT RCT, Flood et al (2005) concluded that occupational therapy and social work were equally cost effective in enabling older people to remain in their own home.

It was acknowledged that determining the cost effectiveness of housing adaptations and equipment for older people is extremely complex because of the differences in housing stock and cost-effective adaptations are only possible in certain types of housing (Heywood 2001, Lansley et al 2004, Mountain 2004). Timescales were also considered important when evaluating the cost effectiveness of adaptations, which can take a considerable length of time to complete (Flood et al 2005). In addition, preventing delay in adaptations provision can reduce costs in other areas: for example, the need for care or reassessment due to deterioration in the person's needs. In other words, paying out for adaptations should reduce other spending as long as this is done in a timely manner (Heywood and Turner 2007).

Where rehabilitation and reablement services are concerned, evaluations tend to consider the cost effectiveness of the service as a whole. Their perceived effectiveness in reducing service-users' dependency, home care packages, admission to hospital, or residential or nursing home care has been reported (CSED 2007, Francis et al 2011, Glendinning et al 2008, Latif 2011, McLeod and Mair 2009, Rabiee and Glendinning 2011). What now needs to be determined is the extent to which cost effectiveness is related to occupational therapy involvement, which is regarded as central to social care reablement (Francis et al 2011, Glendinning et al 2008, Walden 2011a).

\section{Evaluation and audit}

Examples from service evaluations and audits have been used in the sections above to illustrate the perceived effectiveness and outcomes of occupational therapy interventions and services for older people. However, several authors have recommended what needs to be done in terms of evaluation in future. In relation to policy implementation, Ridout and Mayers (2006) called for more active auditing in order to evidence the client-centeredness of occupational therapy practice in the light of the single assessment process (SAP); Sackley et al (2009) pointed to a lack of audit of the use of eligibility criteria. In order to evidence effectiveness across services, Skelton (2006) suggested that a comprehensive database of occupational 
therapy services and staff in local authorities was needed. In a study of waiting lists in a Scottish authority, Wilson (2010) recommended that local authorities should regularly audit and evaluate occupational therapy services in order to improve practice, and that best practice should address timescales for provision after assessment. In relation to reablement, audits should give detail of the goals and interventions that are used to achieve them, together with professional input.

\section{Discussion}

The localized nature of local authority social care services and geographical variability across Great Britain inevitably has an impact on how occupational therapy services are organized and delivered. Such variability makes benchmarking and service comparisons problematic. In addition, because occupational therapists in social care work in collaboration with other professions (and in some instances their services are integrated with, for example, housing, social work, or home care), disaggregating the effectiveness and cost effectiveness of occupational therapy interventions from others is also problematic.

Despite this, the review established that there is a growing body of evidence to support the perceived effectiveness of social care occupational therapy services in different localities, and that the benefits for older service users were identifiable. Much of this evidence, however, came from small-scale localized studies (mostly conducted in England), from which it was difficult to generalize. The transferability of findings from these studies was also difficult where there was a lack of description of the context and location. These studies were, however, specifically related to occupational therapy, and collectively provided worthwhile evidence. The larger-scale studies, mostly conducted within and across organizations, were more generalizable, but tended to address broader issues that involved occupational therapists. By taking a flexible and pragmatic approach, in this review it was possible to establish patterns in the findings across studies, and the discussion-based and opinion pieces reviewed, together with policies and reports, added further detail on specific topics. However, several authors identified that more work is needed to address the difficulties in isolating the effectiveness of occupational therapy from other aspects of social care services (Glendinning and Newbronner 2008, Heywood and Awang 2011, Heywood and Turner 2007, Latif 2011, Walden 2011a).

\section{Critical evaluation}

A major limitation of this review was accessing literature that was specifically relevant to the topic. There was little published literature available that was specific to the effectiveness of occupational therapy in social care. To try and address this, the search terms were expanded as the review progressed. In terms of addressing the research questions, it was found that the small-scale studies, which tended to use one data collection method and were restricted to one location, were specifically related to occupational therapy, whereas the larger-scale studies, which utilized mixedmethods or RCTs, addressed broader issues, and it proved difficult to disaggregate occupational therapy from other services. In addition, most of the published reports and research-based literature focused on services in England. In order to obtain a comprehensive picture of occupational therapy services in all three countries, the research team also acquired unpublished literature. This proved easier to achieve in Wales and Scotland, which helped to offset the concentration of published literature on services in England. However, the search cannot claim to be exhaustive, and the quality of literature as a whole was variable, as identified in the quality section above.

\section{Recommendations}

Further research is needed into:

- The effectiveness of occupational therapy in social services and whether it is possible to disaggregate it from other services.

- The impact of organizational constraints on the effectiveness of occupational therapy social care services.

- The effectiveness of rehabilitation and reablement social care teams where occupational therapists are involved.

\section{Implications for practice}

Occupational therapists need to:

- Acknowledge the importance of their role in providing equipment and adaptations that contribute to older service users' occupational engagement, independence, health, and wellbeing.

- Be more proactive in publicizing the effectiveness of their interventions more widely.

- Proactively engage in wider policy and organizational issues.

- Investigate the appropriate use of outcome measures for occupational therapy in social care services.

- Carry out regular audits and evaluations to provide evidence of the effectiveness of their services.

- Publish the evidence supporting the effectiveness of their interventions.

\section{Conclusion}

Overall, this literature review has identified a high level of service user satisfaction, and that once timely occupational therapy services have been accessed and delivered, they are perceived to be effective and preventative for older people. It is also evident that occupational therapy can be cost effective by improving and maintaining older people's independence and preventing dependency on other services. However, the localized, complex, and collaborative nature of social care services across Great Britain will continue to make it difficult to prove the effectiveness of occupational therapy in isolation from other local authority services and further work is needed to address this. 


\section{Key findings}

- Social care occupational therapy interventions maintain older people's independence at home.

- Timely interventions can be cost effective for other services.

- Service user satisfaction is high once services are received.

\section{What the study has added}

This study contributes to the evidence base for the effectiveness and cost effectiveness of social services' occupational therapy in maintaining older people's independence at home and preventing dependency on other services.

\section{Conflict of interest: None declared.}

Funding: This research received funding support from the United Kingdom Occupational Therapy Research Fund (UKOTRF), which had no other role in the direction of the study.

Research ethics: Ethical approval was not required for this study.

\section{References}

Armstrong S (2001) Recording and evaluating occupational therapy outcomes in a social services setting. Journal of Integrated Care, 9(4), 39-43.

Awang D (2002) Older people and participation within disabled facilities grant processes. British Journal of Occupational Therapy, 65(6), 261-268.

Brittle N, Lett K, Littlechild R, Sackley C (2007) The disability profile of adults who receive adaptive equipment from local authority occupational therapy services. British Journal of Occupational Therapy, 70(11), 479-482.

Care Services Efficiency Delivery Programme (2007) Homecare re-ablement assessment tools and satisfaction surveys. London: Care Services Improvement Partnership.

Chamberlain E, Evans N, Neighbour K, Hughes J (2001) Equipment: is it the answer? An audit of equipment provision. British Journal of Occupational Therapy, 64(12), 595-600.

College of Occupational Therapists (2008) Position statement. The value of occupational therapy and its contribution to adult social service users and their carers. London: COT.

College of Occupational Therapists (2010) COT/BAOT Briefing 127. Government structures in Northern Ireland. London: COT.

Department of Health (2001) National Service Framework for Older People. London: $\mathrm{DH}$.

Department of Health (2008) Putting People First — working to make it happen: adult social care workforce strategy — interim statement. London: DH.

Equipu (Social work and NHS service) (2010) DART/IRIS service user survey outcomes report April 2010. Service user survey 2009-10 and equipment/ adaptation - cost benefit analysis - local examples. Glasgow: EQUIPU (unpublished). Available at: $h$ ttp://uww.cordia.co.uk/Our-Services/EquipU.aspx.

Flood C, Mugford M, Stewart S, Harvey I, Poland F, Lloyd-Smith W (2005) Occupational therapy compared with social work assessment for older people. An economic evaluation alongside the CAMELOT randomised controlled trial. Age and Ageing, 34(1), 47-52.

Forsyth K, Hamilton E (2008) Social services occupational therapists' view of practice and integration with health: a survey. British Journal of Occupational Therapy, 71(2), 64-71.

Francis J, Fisher M, Rutter D (2011) Reablement: a cost effective route to better outcomes. Research briefing 36. London: Social Care Institute for Excellence.
Glendinning C, Clarke S, Hare P, Maddison J, Newbronner L (2008) Progress and problems in developing outcomes-focused social care services for older people in England. Health and Social Care in the Community, 16(1), 54-63.

Glendinning C, Newbronner E (2008) The effectiveness of home care reablement — developing the evidence base. Journal of Integrated Care, 16(4), 32-39.

Great Britain. Parliament (1970) Chronically Sick and Disabled Persons Act 1970. London: HMSO.

Grisbrooke J, Scott S (2009) Moving into housing: experiences of developing a specialist occupational therapy posts in local authority housing departments. British Journal of Occupational Therapy, 72(1), 29-36.

Heaton J, Bamford C (2001) Assessing the outcomes of equipment and adaptations: issues and approaches. British Journal of Occupational Therapy, 64(7), 346-356.

Heywood F (2001) Money well spent: the effectiveness and value of housing adaptations. Bristol: The Policy Press and the Joseph Rowntree Foundation.

Heywood F (2004) The health outcomes of housing adaptations. Disability and Society, 19(2), 129-143.

Heywood F, Turner L (2007) Better outcomes, lower costs. Implications for health and social care budgets of investment in housing adaptations, improvements and equipment: a review of the evidence. Leeds: Office for Disability Issues, Department for Work and Pensions.

Heywood F, Awang D (2011) Developing a housing adaptation genome project. British Journal of Occupational Therapy, 74(4), 200-203.

Hunt D, Cook M (2001) Caseload monitoring for social services occupational therapists. British Journal of Therapy and Rehabilitation, 8(9), 326-330.

Information Centre for Health and Social Care (2011) Personal Social Services: Staff of Social Services Departments, England — as at September 2011. Available at: $h$ ttp://mww.hscic.gov.uk/catalogue/PUB05801 Accessed 03.04.12.

Inverclyde Council (2010) Community rehabilitation service report. (Unpublished) Greenock: Inverclyde Council.

Jones KC, Baxter K, Curtis LA, Arksey H, Forder JE, Glendinning C, Rabiee P (2009) Investigating the longer term impact of home care reablement services: the short-term outcomes and costs of home care re-ablement services. Interim report: Working Paper Number DHR 2378. York: Social Policy Research Unit, University of York.

Kent J, Payne C, Stewart M, Unell J (2000) External evaluation of the home care reablement pilot project. (Unpublished) Leicester: Centre for Group Care and Community Care Studies, De Montfort University.

Lansley P, McCreadie C, Tinker A (2004) Can adapting the homes of older people and providing assistive technology pay its way? Age and Ageing, 33(6), 571-576.

Latif Z (2011) Cost benefit analysis of the occupational therapists impact on reablement in Nottingham City. Nottingham: [s.n.] Available at: http://www.thinklocalactpersonal.org.uk/_library/cost_benefit_analysis. OT.reablement_19-10-2011_Zaid_Latif.doc Accessed 21.02.12.

Lett K, Sackley C, Littlechild R (2006) The use of fair access to care services' eligibility criteria for equipment provision within local authorities in England. British Journal of Occupational Therapy, 69(9), 420-422.

Littlechild R, Bowl R, Matka E (2010) An independence at home service: the potential and the pitfalls for occupational therapy services. British Journal of Occupational Therapy, 73(6), 242-250.

Long AF, Godfrey M (2004) An evaluation tool to assess the quality of qualitative research studies. International Journal of Social Research Methodology, 7(2), 181-196.

McLeod B, Mair M (2009) Evaluation of city of Edinburgh council home care re-ablement service. Edinburgh: Scottish Government Social Research. 
Miller A, Foulkes D (2011) Occupational therapy intake team audit. (Unpublished) Abergele Social Services: Conwy Council.

Mountain G (2000) Occupational therapy in social services departments: a review of the literature. London: College of Occupational Therapists.

Mountain G (2004) Using the evidence to develop quality assistive technology services. Journal of Integrated Care, 12(1), 19-26.

National Institute for Health and Clinical Excellence (2009) Methods for the development of NICE public health guidance. 2nd ed. London: NICE.

Office for National Statistics (2012) Population ageing in the United Kingdom, its constituent countries and the European Union. London: Office for National Statistics.

Rabiee P, Glendinning C (2011) Organization and delivery of home care re-ablement: what makes a difference? Health and Social Care in the Community, 19(5), 495-503.

Reid-Howie Associates (2000) Users' views of the occupational therapy service in Fife. Glasgow: Dunfermline Forum on Disability.

Ridout A, Mayers C (2006) Evaluation of the implementation of the single assessment process and its impact on occupational therapy practice. British Journal of Occupational Therapy, 69(6), 271-280.

Riley J, Boniface GE, Cox J (2012) The effectiveness of occupational therapy local authority social services' interventions for older people in Great Britain [Project report]. London: College of Occupational Therapists.

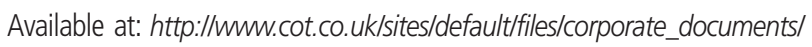
public/CR-Riley-Exec-Sum.pdf Accessed 18.11. 13.

Rychetnik L, Frommer M, Hawe P, Shiell A (2002) Criteria for evaluating evidence on public health interventions. Journal of Epidemiology and Community Health, 56(2), 119-127.

Sackley C, Lett K, Littlechild R (2009) Equipment provision by local authority occupational therapy teams using the Fair Access to Care Services eligibility framework: a vignette and interview study. British Journal of Occupational Therapy, 72(6), 259-265.

Sainty M, Lambkin C, Maile L (2009) 'I feel so much safer': unravelling community equipment outcomes. British Journal of Occupational Therapy, 72(11), 499-506.

Scottish Executive (2006) Changing lives: report of the 21st century social work review. Edinburgh: Scottish Executive.

Scottish Executive (2007a) All our futures: planning for a Scotland with an ageing population. Edinburgh: Scottish Executive.

Scottish Executive (2007b) Co-ordinated, integrated and fit for purpose: a delivery framework for adult rehabilitation in Scotland. Edinburgh: Scottish Executive.

Scottish Government (2011) Social work services staff — workforce. Available at: $h$ ttp://www.scotland.gov.uk/Topics/Statistics/Browse/Children/ TrendWorkforce Accessed 02.04.12.
Skelton J (2006) Through critical appraisal determine the themes and outcomes from best value reviews of occupational therapy services within the social care setting in England and their usefulness. (Unpublished MSc dissertation). London: London Metropolitan University.

Social Care Institute for Excellence (2010) SCIE systematic research reviews: guidelines. 2nd ed. London: SCIE. Available at: http://www.scie.org.uk/ publications/researchresources/rr01.asp Accessed 01.08.11.

Social Services Improvement Agency (Wales) (2011) Demonstrating improvement through reablement. Phase 1 overview report. Cardiff: SSIA.

Stewart S, Harvey I, Poland F, Lloyd-Smith W, Mugford M, Flood C (2005) Are occupational therapists more effective than social workers when assessing frail older people? Results of CAMELOT, a randomised controlled trial. Age and Ageing, 34(1), 41-46.

Stubbs R, Atwal A, McKay E (2004) Evaluating the community dependency index in a social service context. International Journal of Therapy and Rehabilitation, 11(6), 281-286.

Thomas J, Harden A (2008) Methods for the thematic synthesis of qualitative research in systematic reviews. BMC Medical Research Methodology, $8(45), 1-8$.

Tucker S, Brand C, O'Shea S, Abendstern M, Clarkson P, ... Challis D (2011) An evaluation of the use of self-assessment for the provision of community equipment and adaptations in English local authorities. British Journal of Occupational Therapy, 74(3), 119-128.

University of Oxford (2005) Critical Appraisal Skills programme: making sense of the evidence. Oxford: University of Oxford.

Walden D (2011a) Redesigning reablement: why these services need to focus on patient independence. Health Service Journal. Available at: http://m.hsj.co.uk/5032542.article Accessed 14.11.13.

Walden D (201 1b) A better way back to everyday life. Health Service Journal, 8, 26-27.

Weetman RP (2002) Occupational therapy rehabilitation scheme. (Unpublished). Mold: Flintshire Social Services.

Welsh Assembly Government (2007) A strategy for social services in Wales over the next decade. Fullfilled lives, supportive communites. Cardiff: Welsh Assembly Government.

Welsh Assembly Government (2008) The strategy for older people in Wales 2008-2013. Cardiff: Welsh Assembly Government.

Welsh Government (2011) Local authority social services — staff numbers, March 2011. Available at: http://wales.gov.uk/docs/statistics/2011/ 111012sdr1842011en.pdf Accessed 02.04.12.

Wilson J (2010) The effects on service users and occupational therapists of waiting times for occupational therapy services within a local authority social work service. (Unpublished MSc dissertation). Edinburgh: Queen Margaret University. 